\title{
The effects of shock punishment conditions on the threshold for an associated auditory stimulus
}

\author{
Martin Katahn, Leland Thune and Rachel Doody'
}

VANDERBILT UNIVERSITY

\begin{abstract}
Abstraet
When avoidance of shock seemed possible, Ss exhibited significantly lower thresholds for an associated auditory stimulus compared with Ss in a noavoidance condition. No-avoidance Ss showed significant habituation of spontaneous GSR activity, an effect not obtained in the avoidance group.
\end{abstract}

\section{Problem}

Solley \& Murphy (1960) state that if a perceived stimulus closely precedes some punishing stimulus event and escape or avoidance of the punishing stimulus is possible, then that perceived stimulus will become dominant in the perceptual field. If no escape or avoidance is possible, then that perceived stimulus will becomes less dominant in the perceptual field. These effects. have also been labeled perceptual "emphasis" and "de-emphasis."

Supporting studies have employed complex visual stimuli and procedures which allow for interpretations not based upon the escape, no-escape possibility. In a study by McNamara, Solley, \& Long (1958) the escape group experienced less total shock than the no-escape group. Overall results indicated that the less the shock, the greater the perceptual emphasis. In a study by Dulany (1957), the shock followed Ss' responses when the percept itself was not present in the field. This procedure might operate directly upon habit strengths of response tendencies rather than upon dominance of percepts.

The present study tests the Solley-Murphy hypothesis in an avoidance/no-avoidance paradigm which equalizes total shock punishment. A simple auditory stimulus is used as the associated, perceived stimulus, accompanying shock punishment.

\section{Procedure}

Ss were 30 female undergraduate psychology students, six Ss serving in each of five conditions. For an avoidance group, a 2000 cycle tone was paired with shock using a CS-UCS interval of 2.5 sec., as Ss performed on a learning task. The task apparatus consisted of a $5 \times 5$ matrix of buttons connected to a corresponding matrix of lights visible to the experimenter in the control room of a two-room sound treated suite. The tone was a signal for the $\mathrm{S}$ to press some combination of two buttons on the matrix. When S discovered certain predetermined combinations she received, alternately, three or four shock-free trials by pressing these same buttons in response to the tone signals which followed. When the shock began again, S's task was to search for some other combination of buttons through which she could avoid shock on another three or four trials. Ss had to respond within the $2.5 \mathrm{sec}$. tone duration interval, as well as with the correct buttons, in order to be so rewarded. Ss continued in this way until a total of 60 shocks had been received.

There were two types of no-avoidance conditions, in which tone was always paired with shock. In an instrumental no-avoidance group, Ss performed on the learning task, with shock following every response for 60 trials. In a classical no-avoidance condition the learning task was not used. Ss in this group received 60 presentations of the tone for $2.5 \mathrm{sec}_{\text {. }}$, followed immediately by shock.

A tone-alone control group received 60 presentations of the tone, no shock, and did not perform on the task. This group was included to control for increased familiarity with tone. A tone-shock control group received 30 trials of shock alone, 60 tone presentations, and another 30 shocks. The learning task was not used. This group was included to control for the effects of shock on tone thresholds when shock is not paired in a meaningful or conditioning relationship with tone.

Previous to, and immediately after the various treatments, thresholds were determined using the mean of 10 ascending-limits-method trials. A Beltone 15-A Audiometer was used to generate the tone, which was controlled through the timing circuit of a GraysonStadler GSR unit, model E-664. Continuous GSR records were obtained during both threshold measurements. Spontaneous GSRs were defined as non-threshold related deflections of at least $2 \mathrm{~mm}$, occurring at a minimum rate of $1 \mathrm{~mm}$ per sec. The intensity of tone used during the experimental treatments was $10 \mathrm{db}$ above the individual's just determined threshold. Shock generated by the GSR unit for .5 sec., was administered to the right forearm through coin electrodes and was the strongest intensity the $\mathrm{S}$ would endure.

\section{Results and Discussion}

The avoidance group exhibited a decreased threshold for the tone following the experimental treatment compared with their own pre-treatment threshold (Table 1). Both no-avoidance groups exhibited higher thresholds, while controls showed little change. Since the Solley-Murphy hypothesis makes no distinction between types of avoidance or controls, statistical comparisons were made between the avoidance group, the combined no-avoidance groups, and the combined controls. The over all analysis of variance of difderences between pre- and post-treatment thresholds for the three conditions was significant $(F(2 / 27)=5.92$; 
Table 1

Mean Change in Auditory Threshold and in Spontaneous GSR Activity

$\begin{array}{lcc}\text { Groups } & \begin{array}{c}\text { Mean threshold } \\ \text { change, db's }\end{array} & \begin{array}{c}\text { Mean change in } \\ \text { spontaneous GSR } \\ \text { deflections }\end{array} \\ \text { Avoidance } & -1.09 & -0.05 \\ \text { Instrumental no-avoidance } & +1.16 & -1.36 \\ \text { Classical no-avoidance } & +1.13 & -1.82 \\ \text { Tone alone control } & +0.05 & -1.03 \\ \text { Tone shock control } & -0.22 & -1.65\end{array}$

$\mathrm{p}<.05)$. The most pertinent comparison for the theory is between avoidance and no-avoidance conditions. While the mean difference between these two groups is only about $2.25 \mathrm{db}$, Ss were highly consistent in the direction of the changes $(t=3.31 ; p<.005$, onetail test). Thus, a sensitization effect appears to have occurred as a result of the avoidance treatment, while some form of perceptual de-emphasis or de-sensitization seems to have resulted from the no-avoidance treatment. These results for avoidance and no-avoidance conditions have since been replicated in our laboratory by another experimenter, with minor variations in the procedures.

Spontaneous GSR measurements were obtained by counting the number of non-threshold related deflections in $75 \mathrm{sec}$. time blocks during threshold determinations. The number of deflections in the avoidance group showed little change from pre- to post-treatment threshold determination (Table 1). All other groups showed some habituation of GSR activity. The analysis of variance for the avoidance group, combined no-avoidance groups, and combined controls were significant $(F(2 / 27)=3.55$, $\mathrm{p}<.05)$. Evidently autonomic activity remains high when $S$ attempts to avoid punishment and his attempts seem to be at least partially successful. For noavoidance groups, the reduction in autonomic activity may be an autonomic correlate of repression attempts at the psychological level. This is speculative, of course, since the controls also show considerable reduction in autonomic activity. However, the groups which show the greatest reduction are those which ostensibly had uncontrollable shock: the no-avoidance groups and the tone-shock control. The lesser re- duction which occurred for the tone-alone group might reflect fatigue or tension reduction as Ss habituated to the experimental situation. Other experiments are in progress which may lead to more definitive interpretations.

\section{References}

DULANY, D. E. Avoidance learning of perceptual defense and vigilance. J. abnorm. soc. Psychol., 1957, 55, 333-338.

MCNAMARA, H. J., SOLLEY, C. M., \& LONG, J. Effects of punishment (electric shock) upon perceptual learning. J. abnorm. soc. Psychol., 1958, 57, 91-98.

SOLLEY, C. M., \& MURPHY, G. Development of the perceptual world. New York: Basic·Books, 1960.

\section{Note}

1. We would like to express our appreciation to the Bill Wilkerson Hearing and Speech Center, Nashville, Tennessee, for the use of their facilities and equipment.

\section{Errata}

TRAPOLD, M.A., CARLSON, J. G., \& MYERS, W. A. The effect of noncontingent fixed- and variable-interval reinforcement upon subsequent acquisition of the fixedinterval scallop. Psychon. Sci., 1965, 2, 261-262-The fourth and fifth sentences, beginning with line 10, under Results and Discussion should read as follows: "Using an error estimate based upon all of the data in this overall analysis (Lindquist, 1954, p. 272), the following pattern of .05-level significant differences emerged for each of the three possible pairwise comparisons among the three groups on each of the 15 days of testing: Group FI had significantly larger scallops indices than Group N on days 2 through 5 and than Group VI on days 3 through 6 and day 10. Group VI had significantly smaller scallop indices than Group $\mathrm{N}$ on days 4,6 , and 8 through 10 .

BROWN, S. C., \& BROWN, PENNY. Comparison of successive and simultaneous methods of pair presentation in paired-associate learning. Psychon. Sci., 1965, 2, 309-310-In the first sentence under Method, the number of Ss should be 16, not 24 . 